\title{
A survey analysis of farmer practices and perceptions of zero-grazing on Irish dairy farms
}

\author{
C. Holohan, ${ }^{1 *} \odot$ T. Russell, ${ }^{2} \odot$ F. J. Mulligan, ${ }^{3} \odot$ K. M. Pierce, ${ }^{1}{ }^{\oplus}$ and M. B. Lynch ${ }^{1} \odot$ \\ ${ }^{1}$ School of Agriculture and Food Science, University College Dublin, Lyons Farm, Lyons Estate, Celbridge, Naas, Co. Kildare, Ireland W23 ENY2 \\ ${ }^{2}$ School of Agriculture and Food Science, University College Dublin, Belfield, Dublin 4, Co. Dublin, Ireland \\ ${ }^{3}$ School of Veterinary Medicine, University College Dublin, Veterinary Science Centre, Belfield, Dublin 4, Co. Dublin, Ireland
}

\begin{abstract}
Zero-grazing (ZG; the mechanical harvesting and feeding of fresh grass) is increasingly used in grassbased milk production systems alongside conventional grazing. It allows farmers to supply fresh grass from land parcels that are outside of the main grazing block during seasonal shortages and periods when climatic conditions limit animal grazing opportunities. The objective of this study was to establish an understanding of current ZG practices on Irish dairy farms, to capture farmer perceptions on the implementation of this management practice, and to identify farmer knowledge requirements on ZG. An online survey was distributed and completed by 130 dairy farmers who use or have used ZG. Zero-grazing was used alongside conventional grazing by $92 \%$ of respondents. These farms were particularly fragmented, with between 1 and 14 separate land blocks. Respondents felt ZG helped them overcome fragmentation, increase grass use, and extend grass feeding in spring and autumn. However, extra cost and time input associated with $\mathrm{ZG}$ were recognized as key challenges. The majority of respondents rated current technical information available on ZG in the Republic of Ireland as "poor" or "very poor," and knowledge deficits were identified in the areas of cost analysis, grass management and productivity, cow productivity, cow health and nutrition, and soil fertility.
\end{abstract}

Key words: dairy cow, pasture, zero-grazing, survey, knowledge

\section{INTRODUCTION}

In temperate regions such as Ireland, grass provides a comparatively low-cost and sustainable diet for dairy cows (Läpple et al., 2012; O'Brien and Hennessy, 2017). The relative cost of pasture as a feed source for livestock

Received June 26, 2020.

Accepted December 21, 2020.

*Corresponding author: conor.holohan.1@ucdconnect.ie production compared with grass silage and concentrate has been reported as 1:1.8:2.4, respectively (Finneran et al., 2010), and farmers are encouraged to capitalize on the large amounts of grass that can be grown. In Ireland, grass growth exceeds the European average by more than one-third, and farms can produce between 12 and $16 \mathrm{t}$ of grass DM per hectare over a long growing season (O'Donovan et al., 2010). The grass growing season runs from early spring until late autumn, and farmers target a 300-d grazing season (Kennedy et al., 2009). However, soil type and regional climatic conditions can result in grazing season lengths as low as 220 d in some areas (O'Loughlin et al., 2008).

Although well-managed grazed grass is the most economical feed available for dairy cows (Hanrahan et al., 2018), an increasing number of farmers are choosing to incorporate zero-grazing $(\mathbf{Z G})$ into their farming systems. It is thought that the key drivers for the uptake of this management practice have been to increase the proportion of fresh grass in the diet and as a management tool for fragmented grazing land, expanding herd sizes, and, in some cases, robotic milking systems (Rankin, 2018). Zero-grazing (also known as "cut and carry" or "green chop") is an alternative feeding method in which fresh grass is cut and fed directly to housed cows. The fresh grass is typically cut standing by a purpose-built machine that also transports the grass from the field (Agrisearch, 2018). The concept of ZG originates in mainland Europe, where it is typically used to supplement the dairy cow diet with fresh grass in fully confined systems. These farms are characteristically more intensive than grazing farms, whereby they have larger herd sizes and supply highly controlled diets of concentrates and stored forages such as grass or maize silage to achieve high milk yields (Kristensen et al., 2005; Arsenault et al., 2009; Meul et al., 2012). Less, however, is known about the use of ZG in tandem with conventional grazing systems in temperate regions such as Ireland.

Seasonal pasture-based milk production predominates in Ireland. Cows are typically maintained outdoors for up to $300 \mathrm{~d} / \mathrm{yr}$, grazing fresh pasture during the warmer 
months and dried off and housed indoors in the winter months leading up to the spring-calving period (Dillon et al., 1995; O'Donovan et al., 2011). The aim of this system is to calve the herd in spring just before the flush of pasture growth, attempting, as much as possible, to match the seasonal supply of pasture and the herd intake demand (Macdonald et al., 2008). Despite being the most economical means of feeding dairy cows in Ireland, the implementation of pasture-based systems is not without its challenges (Ferris, 2007; Hurtado-Uria et al., 2013; Wilkinson et al., 2020) and requires flexible approaches and adaptive management (Shalloo et al., 2018). Meteorological conditions, for instance, have a major influence on grass growth and grazing conditions in Ireland (Hurtado-Uria et al., 2013), and going forward, feed supply and nutritive value in pasture-based systems will be particularly vulnerable to changes in climate (Lee et al., 2013). This could see increasingly unpredictable weather conditions and sporadic feed deficits, necessitating the use of conserved forages and concentrates to meet herd demand. Alternatively, ZG may have a role in introducing or maintaining fresh grass in the diet when grass supply on the grazable area adjacent to the milking parlor (known as the grazing platform) does not meet herd demand.

In pasture-based systems, the size of the grazing platform typically dictates stocking rate and the quantity of grazed grass available to the dairy herd (O'Brien and Hennessy, 2017). This has become a key limitation to dairy expansion in Ireland since the abolition of the European Union milk quota regimen in 2015 (Ruelle et al., 2018). Many pasture-based dairy farms in Ireland have a fragmented land base, whereby they consist of multiple discrete land parcels, many of which are often inaccessible for grazing by the dairy herd. These external land parcels (sometimes known as "outblocks") are typically used for young stock rearing and conserved forage production (Patton et al., 2016). Studies have shown that, when compared with the grazable area accessible to the milking herd, these external land parcels are associated with increased costs, management complexity, and reduced farm productivity (O'Donnell et al., 2008; del Corral et al., 2011). Farmers may decide to adopt alternative production strategies in such cases where land fragmentation is an impediment (O'Brien et al., 2012), and ZG is one option (Kristensen et al., 2005; van Vuuren and van den Pol-Van Dasselaar, 2006; Rankin, 2018). In terms of the viability of $\mathrm{ZG}$, there has been relatively little appraisal carried out to date on its use in pasture-based dairy systems. It is acknowledged that although there is potential to use more grass, the conditions required for this management practice to be beneficial to a farm business are currently unclear (Lee and Roberts, 2014). The objectives of this study were to establish an understanding of the current use of ZG on Irish dairy farms, to capture farmer perceptions on the implementation of this management practice at the farm level, and to identify knowledge requirements of farmers on ZG.

\section{MATERIALS AND METHODS}

\section{Survey Design}

An online survey was developed and distributed to dairy farmers across the Republic of Ireland in spring 2019. The survey was created using Google Forms (www.google.com/forms) in a format compatible with desktop and mobile devices, and followed Dillman's tailored design survey protocols (Dillman et al., 2014). The survey was anonymous and did not involve the collection of any identifiable data. When the first phase of survey design was complete, it was pretested with a group of 10 participants to determine usability as per Converse and Presser (1986). Final survey design was then refined based on feedback relating to question clarity, question order and flow, skip patterns, and timing. The final survey was divided into 5 main sections: (1) farm and farmer characteristics, (2) grassland management, (3) ZG practices, (4) farmer perceptions, and (5) knowledge requirements. In total, participants were asked 56 questions, with 44 of these being multiplechoice, 10 open-ended, and 2 ordinal. Sections 1, 2, and 3 were predominantly multiple-choice questions, and in sections 4 and 5, participants were asked open-ended questions to gain an understanding of their perceptions and opinions around ZG.

\section{Sampling}

The population considered in the survey included dairy farmers from across the Republic of Ireland. According to the Central Statistics Office (2016), there are a total of 16,100 specialist dairy farms in Ireland, whereby dairy is the main farming enterprise. Purposive sampling (Tongco, 2007) was initially used for participant selection. To align with the study objectives, it was decided that only dairy farmers who use or have previously used ZG would be targeted. Following telephone interviews with ZG machine suppliers, it was estimated that the number of farmers who use ZG in Ireland is approximately 2,000 ( $12 \%$ of dairy farmers). Given the relatively small size and geographical spread of the target population, snowball sampling was also used, whereby participants were asked to forward the survey link to other dairy farmers who use ZG (Gerlitz and Rieder, 2013). Based on the estimated population size of 2,000, it was calculated that 129 responses would 
be required to give a confidence level of $90 \%$ and a margin of error of $7 \%$.

\section{Survey Distribution}

The survey was distributed in 2 phases; phase 1 in January 2019, and phase 2 in July 2019. Both phases used 2 forms of social media as the primary distribution platform. In phase 1, a link to the online survey was distributed on Twitter. A search was carried out for terms relating to "zero-grazing" and "cut and carry" using the "Search Twitter" function; from this, individual farmers who used ZG were identified and sent the survey link. This method also incorporated snowball sampling. Phase 1 was continued until the number of ZG farmers on Twitter was exhausted and response rates declined. The approach in phase 2 was to use the Teagasc (Irish Food and Agricultural Development Authority) dairy farmer discussion group network to target ZG farmers (Teagasc, 2019). This was conducted via the circulation of an online survey link to farmer discussion group's WhatsApp groups (Ullrich and Khoudary, 2018), and only the members who were using ZG or had previously used ZG were asked to complete the survey. Similar to phase 1, snowball sampling was used, and participants were asked to share the link to other ZG farmers.

\section{Data Preparation and Analysis}

Survey responses were captured on Google Forms on a single electronic datafile, and then transferred from Google Forms to Microsoft Excel 2016 (Microsoft Corporation) for processing. Data cleaning was then conducted to identify and treat errors (Jones and Hidiroglou, 2013). Responses were individually reviewed, and answers which were incomplete, implausible, or numerically outlying were identified and removed. The final step in the data preparation process was to manually code the data so that it could be summarized and analyzed. Qualitative data underwent thematic analysis and was recoded into numerical codes, and then a coding list was generated (Jones and Hidiroglou, 2013). Data analysis was conducted using the IBM SPSS Statistics 24 software package (SPSS Inc.).

\section{RESULTS}

\section{Characteristics of Farms Using ZG}

Respondent Overview. Survey respondents were geographically distributed across the 4 provinces of the Republic of Ireland, with a total of 21 out of 26 counties represented. The highest number of responses were from the main dairy-producing counties of Tipperary,

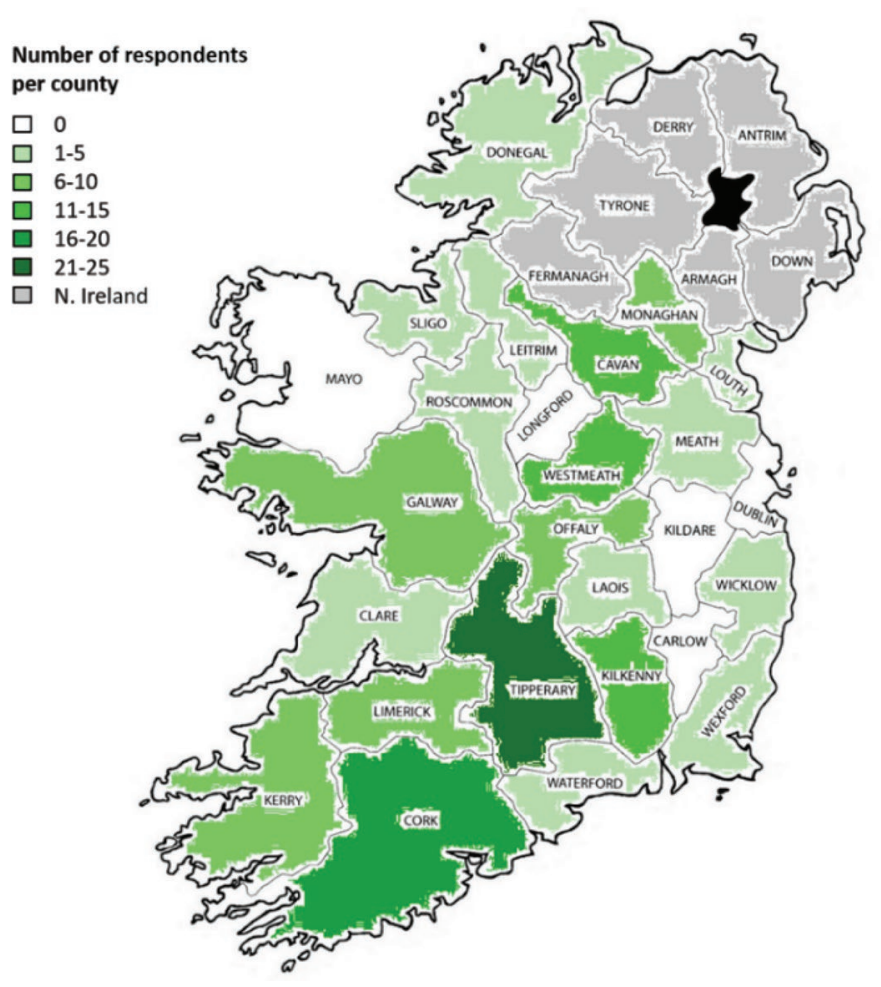

Figure 1. Spatial distribution of survey respondents based on county in the Republic of Ireland.

Cork, and Kilkenny (Figure 1). Age profile of respondents ranged from 19 to 60, with the average being 40. Thirty percent were aged under 35 yr. Sixty-five percent were members of farmer discussion groups.

Production Systems and Technical Performance. The predominant dairy system operated by respondents was spring-calving milk production. Sixtyfive percent of farms were solely in spring-milk production, $30 \%$ operated split-calving systems between spring and autumn, and 5\% calved all year. Conventional twice-a-day milking was carried out on $89 \%$ of these farms, and the remaining $11 \%$ operated automated milking systems (robotic milking). Holstein-Friesian was the main breed on $72 \%$ of farms, followed by British Friesian (12\%), and 15\% had crossbred herds. As Table 1 outlines, the average number of cows on farms surveyed was 146, and annual reported milk yield was 6,702 L. Reported amount of concentrates fed per cow per year was $1,195 \mathrm{~kg}$.

Land Structure. The farms surveyed were 90 ha in size on average (Table 2). Average number of hectares rented was 38, which represented $43 \%$ of total area farmed. On average, these farms consisted of 5 separate land blocks. In terms of soil type, $50 \%$ of respondents indicated that the predominant land type on their farm was moderate (relatively free draining and accessible in 
Table 1. Reported technical performance of farms surveyed

\begin{tabular}{lccc}
\hline Item & $\begin{array}{c}\text { Number } \\
\text { of cows }\end{array}$ & $\begin{array}{c}\text { Milk yield, } \\
\mathrm{kg} / \mathrm{cow} \\
\text { per year }\end{array}$ & $\begin{array}{c}\text { Concentrate } \\
\text { feeding, } \mathrm{kg} / \mathrm{cow} \\
\text { per year }\end{array}$ \\
\hline Minimum & 40 & 4,500 & 500 \\
Maximum & 600 & 10,000 & 3,000 \\
Average & 146 & 6,702 & 1,195 \\
\hline
\end{tabular}

early spring and late autumn). Twenty-seven percent described their land as heavy (limited access in early spring and late autumn), and $23 \%$ stated that their land was mainly light (free draining and accessible most of the year).

\section{Grassland Management}

Perennial ryegrass is the predominant grass species used in dairy production systems in Ireland, accounting for $95 \%$ of grass seed sales (DAFM, 2017), and is hereafter referred to as grass. Survey respondents considered fresh grass to be an important component in their production system. On a scale of 1 to 10 (1 being low and 10 being high), respondents indicated that the importance of fresh grass to their farm business was 9 out of 10 on average. Furthermore, they rated their skill level in grassland management as 8 out of 10. Seventyfour percent of respondents stated that they routinely carried out grass measuring. Of these farmers, $72 \%$ used the "eyeball" technique most often, $17 \%$ used a "rising plate meter", and $11 \%$ used the "quadrat and shears" method. The most common means of removing surplus grass during the grazing season on farms surveyed was "cut and bale" (75\%), followed by premowing (12\%), ZG (9\%), and strip-grazing (4\%).

Average precutting herbage mass of swards when using ZG was $1,785 \mathrm{~kg}$ of DM/ha $(>4 \mathrm{~cm})$, with $68 \%$ of respondents stating that they zero-graze higher grass covers than what they would graze cows at. Typical precutting herbage mass on farms ranged from 1,350 to $2,500 \mathrm{~kg}$ of DM/ha $(>4 \mathrm{~cm})$. Farmers outlined their motivations for zero-grazing at higher precutting herbage mass reported than grazing. The 2 most common reasons were to reduce the distance traveled in the field particularly, "in wet weather and on hills," and to achieve improved grass use. With regard to the lat- ter, some farmers were of the opinion that zero-grazing higher pasture covers optimizes cow performance and sward productivity. Several respondents also indicated that they have previously zero-grazed higher grass covers, "not by choice," but as a consequence of summer drought whereby they were forced to zero-graze grass that was intended for silage production. Some respondents also felt that "increased fiber content" in higher grass covers allowed for improved digestive performance in cows, and others indicated that their ZG machine simply "works better in higher grass covers."

\section{Zero-Grazing Use}

Survey respondents were asked several questions regarding how they use ZG on their farms. On average, respondents had been using ZG for 5 yr. Sixty-nine percent referred to themselves as regular users of ZG, with a further $20 \%$ being occasional users, and $11 \%$ once-off users.

Time of Year. The season within which ZG was used varied among survey participants. Eight percent used ZG on a full-time basis (whereby cows are housed year-round), and $44 \%$ used it on a part-time basis for the duration of the grazing season (whereby cows are routinely fed zero-grazed grass in addition to grazing at pasture). The remaining $48 \%$ of respondents were seasonal users. These farms predominantly used conventional grazing and complimented it with ZG. In terms of these seasonal users (Table 3), $85 \%$ used ZG in autumn, $66 \%$ did so in spring, and $6 \%$ used ZG in summer. Summer users predominantly used ZG in periods of drought when grass growth was impeded and the grazing platform had insufficient grass supplies to feed the herd. Reasons for ZG in spring and autumn largely related to increasing the number of days when grass was in the cow's diet, either by introducing grass earlier in spring or extending grass feeding further into autumn or both. Respondents were also asked which season or seasons they felt ZG was most effective. Spring was selected by $94 \%$ of respondents, autumn was selected by $63 \%$ of respondents, and summer was selected by $34 \%$ of respondents.

Zero-Grazing Practices. The 2 most common methods used to zero-graze were with a farmer-owned purpose-built ZG machine (55\% of respondents) or

Table 2. Land structure on farms surveyed

\begin{tabular}{lcccc}
\hline Item & $\begin{array}{c}\text { Total farm } \\
\text { size, ha }\end{array}$ & $\begin{array}{c}\text { Leased } \\
\text { land, ha }\end{array}$ & $\begin{array}{c}\text { Grazing } \\
\text { platform, }\end{array}$ & $\begin{array}{c}\text { Separate } \\
\text { land blocks }\end{array}$ \\
\hline Average & 90 & 38 & 40 & 5 \\
\hline${ }^{1}$ Land accessible to the milking herd for grazing. & &
\end{tabular}


through the hiring of an agricultural contractor or neighboring farmer ( $43 \%$ of respondents). A small number of survey participants used a mower and forage wagon combination (1.5\%), and 1 respondent used a double-chop forage harvester. Respondents who used an agricultural contractor to carry out ZG stated that the average cost per load delivered was €60. Assuming a typical ZG machine capacity of $6 \mathrm{t}$ (fresh weight), this equated to a cost of approximately $€ 0.01 / \mathrm{kg}$ of fresh grass. When contractors charged on a per-hour basis, the reported cost was $€ 60 / \mathrm{h}$. The main variable in contractor cost was the distance required to travel between farmyard and field. In terms of distance, respondents stated the average round-trip distance traveled to zero-graze grass on their farms was $5 \mathrm{~km}$. This ranged considerably from 0.5 to $38 \mathrm{~km}$. The time of day which respondents chose to ZG varied, with $32 \%$ doing so in the morning, $54 \%$ in the afternoon, and $9 \%$ in the evening. The most common reason for cutting in the morning was "routine," with respondents stating that it was the "next job after milking." Achieving higher grass sugar levels was the main reason why farmers chose to cut in the afternoon.

\section{Perceptions on ZG}

Respondents were asked their reasons for adopting ZG on their farms (Table 4). The most common reason cited was farm fragmentation. In this regard, farmers wished to increase the "use of outblocks" of land to feed the herd, to "avoid walking cows on public roads" or avoid "walking cows long distances," and, in some cases, to "facilitate herd expansion." The second most common reason for farmers to use ZG was to overcome grass deficits on the main grazing block, particularly when grass availability was affected by drought or where "field conditions are too wet" for conventional grazing. The third key driver for ZG on these farms was a desire to reduce grass silage and concentrate feeding in spring and autumn by increasing the proportion of grass in the diet. Farmers also cited a wish to improve cow performance and grass utilization as reasons why they adopted ZG.

Benefits of $Z G$. Several benefits of ZG were identified in the survey (Table 4). The most common benefit cited by respondents was that $\mathrm{ZG}$ allowed them to extend grass feeding in spring and autumn, whereby grass is introduced or maintained in the diet in early spring or late autumn, respectively, to displace grass silage and concentrate feeding. The second most cited benefit was that ZG facilitated herd expansion, as it "takes fragmentation out of the equation" and allows them to "keep more cows" and "increase stocking rate on the milking platform." Perceived improvement in cow performance was the third most common benefit. Zero-grazing also offered farmers a degree of flexibility with their grazing system in terms of filling feed deficits during the grazing season with grass from outside land blocks when required. It was noted among some respondents that it is particularly useful during summer drought or "if grazing conditions turn wet" and there were drier land blocks on the farm where grass can be zero-grazed from. In addition, $65 \%$ of respondents stated that ZG was possible in fields which were too saturated to conventionally graze cows, indicating that in some cases ZG may cause less field damage than grazing cows.

Improvements in grass use was another reported benefit, with farmers highlighting factors such as "less dung pads," "better grass quality," and "quicker regrowth." It was also noted by respondents that zero-grazing silage ground (lands designated for grass silage production) in early spring resulted in "good silage quality" when regrowth was subsequently harvested. In terms of extended grass feeding in spring and autumn, $85 \%$ of respondents stated that ZG allowed them to increase the proportion of grass fed in the diet annually. On average, ZG enabled these farmers to feed fresh grass as the main forage source for 33 additional days per year. As Table 5 outlines, the number of additional days varied depending on the predominant soil type on farms, with heavy soil farms benefiting most.

With regard to cow performance, $85 \%$ of respondents indicated that ZG had an effect (either negative or positive). The ways in which ZG affects cow performance according to respondents are outlined in Table 4. The most cited effects were increased milk yield, higher DMI, and higher milk-solid yield. Farmers also reported improved BCS. Acidosis and digestive upset were reported as negative effects on cow performance.

Challenges of $Z G$. Respondents indicated that there are several challenges associated with ZG that

Table 3. Percentage distribution of seasonal zero-grazing users according to season of use

\begin{tabular}{lcccc}
\hline Item & $\begin{array}{c}\text { Spring and } \\
\text { autumn }^{1}\end{array}$ & $\begin{array}{c}\text { Spring } \\
\text { only }\end{array}$ & $\begin{array}{c}\text { Summer } \\
\text { only }\end{array}$ & $\begin{array}{c}\text { Autumn } \\
\text { only }\end{array}$ \\
\hline Seasonal users, $\%$ & 58 & 8 & 6.5 & 27.5 \\
\hline${ }^{1}$ Spring refers to March, April, and May; autumn refers to September, October, and November.
\end{tabular}


Table 4. Survey participant perceptions on zero-grazing ordered according to rank

\begin{tabular}{|c|c|c|}
\hline Item & Rank & $\begin{array}{l}\text { Number of } \\
\text { responses }\end{array}$ \\
\hline \multicolumn{3}{|l|}{ Reason for zero-grazing } \\
\hline Farm fragmentation & 1 & 88 \\
\hline Grass supply deficits on the grazing platform ${ }^{1}$ & 2 & 46 \\
\hline Feed less silage and concentrates in spring and autumn & 3 & 37 \\
\hline Improve cow performance & 4 & 11 \\
\hline Improve grass utilization & 5 & 8 \\
\hline \multicolumn{3}{|l|}{ Perceived benefits of zero-grazing } \\
\hline Extended grass feeding in spring and autumn & 1 & 36 \\
\hline Facilitate herd expansion & 2 & 28 \\
\hline Improved cow performance & 3 & 25 \\
\hline Flexibility during the grazing season & 4 & 24 \\
\hline Improved grass utilization & 5 & 24 \\
\hline Remove need to walk cows on public road & 6 & 5 \\
\hline \multicolumn{3}{|l|}{ Perceived effect of zero-grazing on cow performance } \\
\hline Increased milk yield & 1 & 53 \\
\hline Higher DMI & 2 & 22 \\
\hline Higher milk solids & 3 & 20 \\
\hline Improved BCS & 4 & 10 \\
\hline Higher milk protein & 4 & 10 \\
\hline Acidosis and digestive upset & 5 & 5 \\
\hline \multicolumn{3}{|l|}{ Perceived challenges of zero-grazing } \\
\hline Time and labor & 1 & 89 \\
\hline Cost & 2 & 60 \\
\hline Machinery and contractor reliability & 3 & 11 \\
\hline Cow health & 3 & 11 \\
\hline Feed variability & 4 & 9 \\
\hline Soil fertility & 5 & 3 \\
\hline \multicolumn{3}{|l|}{ Aspects of zero-grazing requiring more information } \\
\hline Cost & 1 & 43 \\
\hline Grass management and productivity & 2 & 40 \\
\hline Cow productivity & 3 & 33 \\
\hline Cow health and nutrition & 4 & 22 \\
\hline Soil fertility & 5 & 12 \\
\hline
\end{tabular}

${ }^{1}$ Land accessible to the milking herd for grazing.

"add more complexity to grass-based systems." The most prominent of these (Table 4) was the additional time and labor input required with ZG, most notably the time spent "cutting" and "pushing in" grass to the feed face, as well as tasks associated with the management of housed cows such as cubicle bedding and slurry spreading. Farmers who used their own ZG machine also cited the sourcing of "skilled labor" capable of operating the machine as an issue. The second most recognized challenge was the cost of ZG. Several cost factors were highlighted including the initial purchase cost of a ZG machine (if using own machine) and as- sociated running costs or contractor cost for carrying out ZG, slurry spreading, and infrastructural investment to increase slurry storage and feed space if necessary. Another challenge highlighted was the reliance on machinery or contractor to carry out ZG. "Machine breakdowns" and "contractor availability" were noted as issues among some respondents. In terms of cow health, it was stated that lameness, mastitis (due to higher pathogen loads in housed environments compared with pasture grazing), and acidosis were challenges with ZG that "require a keen stockman's eye". In addition, 3 respondents believed ZG may increase

Table 5. Benefits of zero-grazing (ZG) on extended grass feeding based on predominant soil type on farm, ordered according to rank

\begin{tabular}{lccc}
\hline Item & Light $^{1}$ & Moderate $^{2}$ & Heavy $^{3}$ \\
\hline Farms where ZG has allowed extended grass feeding, $\%$ & 6.5 & 27.5 & 58 \\
Additional days, no. & 29 & 32 & 37 \\
\hline
\end{tabular}

${ }^{1}$ Free draining and accessible most of the year.

${ }^{2}$ Relatively free draining and accessible in early spring and late autumn.

${ }^{3}$ Limited access in early spring and late autumn. 
disease risk on the farm, particularly neospora. Feed variability was also seen as a challenge on some farms in terms of changes in grass DM content and quality, depending on weather conditions. Soil fertility was also highlighted as a challenge in relation to soil nutrient imbalances and ground compaction resulting from ZG. Although there were several challenges outlined, $92 \%$ of respondents indicated that they would continue to use $\mathrm{ZG}$ in the future.

\section{Information and Knowledge Requirements on ZG}

In the final section of the survey, respondents were asked several questions relating to the level of information currently available to them on ZG, and about how they can be further supported by research and extension services in the future. When respondents were asked to rate the quality of information available on $\mathrm{ZG}, 1.5 \%$ rated it as "excellent," $8 \%$ rated it as "good," $31.5 \%$ as "Okay," 39\% as "poor," and $20 \%$ as "very poor." The survey highlighted 5 areas that farmers required more information on (Table 4). First, they wished to know the cost of ZG grass in comparison to conventional grazing, grass silage, and TMR feeding. Respondents also felt a comparison between the use of contractor versus owned machine for ZG was needed. Grass management and productivity was also highlighted as an area of interest, and farmers required information on several aspects in this regard, including which grass varieties are best suited to ZG, grass growth and quality when using ZG, grass-use rates, and optimum precutting herbage mass. Respondents also felt that "a lot more research needs to be done on the effects of ZG on the cow." In this regard, farmers expressed a desire to know if ZG can increase cow productivity and by how much. Where higher DMI are observed, farmers wished to understand "what cows do with the all the grass they eat." Regarding cow health and nutrition, farmers required knowledge, particularly on rumen health and the use of rumen buffers, to counteract acidosis. Respondents also required more information on disease risks associated with ZG. In terms of soil fertility, respondents required guidance on nutrient management when using ZG, particularly the maintenance of soil nutrient levels through slurry and chemical fertilizer applications. In addition, farmers wished to understand the effect of ZG on soil compaction and resulting effects on productivity.

\section{DISCUSSION}

\section{Zero-Grazing Farm Characteristics}

Results from this study indicated that farms implementing ZG were characteristically distinct in several ways. First, the proportion of respondents under $35 \mathrm{yr}$ of age was $30 \%$, which is markedly higher than the national average of $5 \%$ (DAFM, 2019), and would suggest that farmers who use ZG tend to be younger. According to McKillop et al. (2018), younger farmers are typically more inclined to adopt and try new technological innovations and management practices (such as ZG in this case). In terms of size, farms that carried out ZG were larger in scale, with the average herd size of 146 cows being notably higher than the national average of 79 (Teagasc, 2018). The average milk 305-d milk yield per cow in Ireland stands at 5,438 kg (Teagasc, 2018), and average yield was $6,702 \mathrm{~kg}$ in this study. Meal feeding of $1,195 \mathrm{~kg} /$ cow per year was marginally lower than the national average of $1,353 \mathrm{~kg}$ (Teagasc, 2018). A shared characteristic among farms surveyed was land fragmentation - something which has been widely regarded as a key limitation for pasture-based dairy farms (O'Donnell et al., 2008; del Corral et al., 2011; Ruelle et al., 2018). On average, these farms consisted of 5 separate land blocks, and this ranged from 1 up to 14 .

Grass is an important resource in Irish dairy systems, and farmers are encouraged to make as much use of it as possible (Läpple et al., 2012). Similarly, farmers who used ZG scored the importance of grass to their business as 9 out of 10, and rated their skill level in grassland management as 8 out of 10. A noteworthy difference in grassland management practices between ZG and grazing was precutting herbage mass. According to O'Donovan and McEvoy (2016), target pregrazing herbage mass for conventional grazing is between 1,300 and $1,600 \mathrm{~kg}$ of $\mathrm{DM} / \mathrm{ha}(>4 \mathrm{~cm})$; however, average precutting herbage mass on farms where $\mathrm{ZG}$ was used was $1,785 \mathrm{~kg}$ of DM/ha $(>4 \mathrm{~cm})$. Farmers cited "less driving" and "improved grass utilization" as their main reasons for doing so.

\section{Practices and Perceptions of ZG}

Although ZG in mainland Europe is predominantly used to supply grass in fully confined systems throughout the growing season (Meul et al., 2012), this study demonstrated that only $8 \%$ of $\mathrm{ZG}$ users in Ireland operate fully confined systems. The remaining $92 \%$ of ZG users are pasture-based farms that use ZG either on a part-time basis throughout the growing season or sporadically in certain periods when grass supply on the main grazing block does not meet herd demand. Spring and autumn were highlighted as the most popular seasons for using ZG, and the key drivers for this were the desire to introduce grass into the diet earlier in spring and to extend grass feeding further into the autumn. This is reflective of Irish dairy industry efforts, which have focused on extending the grazing season in 
spring and autumn to increase the quantity of grass in the diet and decrease the proportion of grass silage and concentrate required (Läpple et al., 2012). The main motive for ZG in the summer period was to overcome drought-induced feed deficits on the grazing platform. In the summer of 2018, Ireland suffered a major meteorological drought that negatively affected grass growth in many regions (Falzoi et al., 2019). This study found that some farmers opted to use ZG during this time, and in some cases were required to travel up to $38 \mathrm{~km}$ (round-trip) to source grass to feed their herds. Going forward, pasture-based dairy farmers may decide to explore the short-term use of ZG as a method for overcoming feed deficits given that such weather events may become more frequent (Lee et al., 2013).

Almost half (45\%) of survey respondents stated that they use a contractor or neighboring farmer to ZG, and this may be an option for farmers in the future where $\mathrm{ZG}$ is only required on a short-term basis and does not justify the purchase of a ZG machine. Looking at the general reasons for $\mathrm{ZG}$ on the farms surveyed, the most common was farm fragmentation, something which was previously thought to be a key driver for the uptake of ZG (Rankin, 2018). External land blocks on fragmented farms are typically used for young stock rearing and conserved forage production (O'Donnell et al., 2008; del Corral et al., 2011), and survey respondents felt they could improve the productivity of these land blocks by using them to feed the dairy herd through ZG.

Based on the experiences of farmers surveyed, the leading benefit of ZG was extended grass feeding in spring and autumn. On average, respondents achieved 33 additional days of grass feeding annually through the use of ZG. Farmers also felt ZG allowed them to expand their herd, thus overcoming a key limitation to dairy farm expansion-land fragmentation (Ruelle et al., 2018). They also highlighted possible benefits to cow performance such as increased milk yield and DMI and improved BCS. Improvements in DMI and BCS could be particularly beneficial to dairy cows in the early-lactation period when energy demand for production is higher than intake can support and the risk of health issues and reproductive disorders is at its largest (Gilmore et al., 2011). Zero-grazing also offered farmers a degree of flexibility with their grazing system in terms of filling feed deficits during the grazing season with grass from outside land blocks when required. Parts of Ireland often experience reduced grass availability in the summer months due to soil moisture deficits and lack of sufficient precipitation (Fitzgerald et al., 2005), and ZG may offer potential in this regard. Farmers also highlighted improvements in grassland productivity and grass use with ZG. According to the survey, grass-silage quality reportedly improved when farmers zero-grazed lands in spring, which were then used for grass silage production. Previous research has shown that grazing (or ZG in this case) to a stubble height of $5 \mathrm{~cm}$ or lower in late autumn or early spring prevents dead vegetation from accumulating in silage swards and helps produce high digestibility silage (O'Kiely, 2014).

With regard to the challenges associated with $\mathrm{ZG}$, the most prominent was the additional time and labor input required for ZG. This may be particularly challenging during the spring-calving period on pasturebased farms when labor demand is at its highest (Deming et al., 2019). The second key challenge identified by respondents was the cost of ZG. Although grazed grass is the cheapest feedstuff available to Irish dairy farmers (Finneran et al., 2010), the economics of ZG are currently unclear. In terms of cow health, it was stated that acidosis is a challenge with ZG. Highly digestible perennial ryegrass contains high concentrations of rapidly fermentable carbohydrate and low concentrations of physical effective fiber that may result in subacute ruminal acidosis (SARA) in dairy cows (O'Grady et al., 2008). Potential increases in DMI associated with ZG may compound this further without the use of dietary products such as buffers to regulate ruminal $\mathrm{pH}$. Lameness and mastitis were also highlighted as cow-health challenges associated with ZG. Risk of lameness may be higher where cows are housed indoors due to the concussive effects of concrete flooring on hooves, or increased contact between hooves and slurry. In terms of mastitis, SCC may be higher due to a greater general pathogen load and reduced hind-limb cleanliness within housed environments (Arnott et al., 2015). These are all key considerations when evaluating the benefits and challenges of ZG.

\section{Knowledge Requirements}

According the EU SCAR report "Preparing for the future AKIS" (EU SCAR AKIS, 2019), the focus of agricultural innovation systems is now on enhancing knowledge flows and strengthening links between research and practice. This study gained valuable perspectives from ZG users on the opportunities and challenges associated with the implementation of this management practice at the farm level and highlighted knowledge deficits that require further examination. In total, $59 \%$ of respondents rated current information on ZG as "poor" or "very poor," indicating that information on this management practice was not sufficient for the majority of those surveyed. In terms of specific knowledge gaps relating to ZG, farmers required further information on 5 key areas: the cost of ZG compared with conventional grazing or silage feeding, grassland 
management and productivity, cow productivity, cow health and nutrition, and soil fertility. Therefore, research and extension efforts in relation to ZG should seek to fill the 5 key knowledge gaps identified in this study. This form of interaction between stakeholders is central to the interactive innovation model and makes the best use of complementary types of knowledge in view of cocreation and dissemination of solutions ready to implement in practice (EU SCAR AKIS, 2019).

\section{CONCLUSIONS}

This study offered a timely insight into the use of ZG on Irish dairy farms. It found that ZG is used in several ways on farms, with the majority of farmers using it on a part-time or seasonal basis, and only a small minority using ZG full-time. Farmers using ZG were younger and typically had larger farms than the national average. Spring was highlighted as the most beneficial time of year to ZG in the temperate grassbased system in Ireland. Almost half of those surveyed used a contractor to carry out ZG, and this may be an option for seasonal ZG use on pasture-based farms in the future, particularly given the costs associated with purchasing and operating ZG machines. Perceived benefits of ZG included extended grass feeding, herd expansion, improvements in cow and sward productivity, and flexibility with grazing systems. While there are several reported benefits, there are also several challenges which need to be addressed, particularly the economic feasibility of ZG. Several knowledge deficits exist among farmers regarding ZG, and there is an apparent need for more information on this management practice. It is recommended that future research and extension efforts focus on the areas of cost analysis, grass management and productivity, cow productivity, cow health and nutrition, and soil fertility in relation to ZG.

\section{ACKNOWLEDGMENTS}

We acknowledge the financial support of the Irish Department of Agriculture, Food and the Marine (Dublin, Ireland) Research Stimulus Fund under the NutriGen project (15S675), and the cooperation of the Teagasc (Carlow, Ireland) Dairy Knowledge Transfer department. The authors have not stated any conflicts of interest.

\section{REFERENCES}

Agrisearch. 2018. Zero-grazing - A best practice guide. Agrisearch. Arnott, G., C. Ferris, and N. O'Connell. 2015. A comparison of confinement and grazing systems for dairy cows: What does the science say? AgriSearch.
Arsenault, N., P. Tyedmers, and A. Fredeen. 2009. Comparing the environmental impacts of pasture-based and confinement-based dairy systems in Nova Scotia (Canada) using life cycle assessment. Int. J. Agric. Sustain. 7:19-41. https://doi.org/10.3763/ijas.2009 .0356 .

Central Statistics Office. 2016. Farm Structure Survey 2016. Accessed Oct. 10, 2019. https://www.cso.ie/en/releasesandpublications/ep/ p-fss/farmstructuresurvey2016/da/fs/.

Converse, J., and S. Presser. 1986. Survey Questions: Handcrafting the Standardized Questionnaire. Sage University Press.

DAFM. 2017. Grass and white clover varieties - Irish recommended list 2017. Accessed Dec. 20, 2020. https://agritech.ie/wp-content/ uploads/2017/04/GrassandWhiteCloverRecommendedListVarietiesforIreland2017210317.pdf.

DAFM. 2019. Annual Review and Outlook for Agriculture, Food and the Marine 2019. Accessed May 15, 2020. https://www.agriculture.gov .ie/media/migration/foodindustrydevelopmenttrademarkets/agri -foodandtheeconomy/publications/annualreviewandoutlook2019/ chapter-2.html.

del Corral, J., J. Perez, and D. Roibas. 2011. The impact of land fragmentation on milk production. J. Dairy Sci. 94:517-525. https:// doi.org/10.3168/jds.2010-3377.

Deming, J., J. Kinsella, B. O'Brien, and L. Shalloo. 2019. An examination of the effects of labor efficiency on the profitability of grassbased, seasonal-calving dairy farms. J. Dairy Sci. 102:8431-8440. https://doi.org/10.3168/jds.2018-15299.

Dillman, D., J. Smyth, and L. Christian. 2014. Internet, Phone, Mail, and Mixed-Mode Surveys: The Tailored Design Method. 4th ed. Wiley.

Dillon, P., S. Crosse, G. Stakelum, and F. Flynn. 1995. The effect of calving date and stocking rate on the performance of springcalving dairy cows. Grass Forage Sci. 50:286-299. https://doi.org/10 $.1111 /$ j.1365-2494.1995.tb02324.x.

EU SCAR AKIS. 2019. Preparing for Future AKIS in Europe. European Commission.

Falzoi, S., E. Gleeson, K. Lambkin, J. Zimmermann, R. Marwaha, R. O'Hara, S. Green, and S. Fratianni. 2019. Analysis of the severe drought in Ireland in 2018. Weather 74:368-373. https://doi.org/ $10.1002 /$ wea. 3587 .

Ferris, C., 2007. Sustainable pasture-based dairy systems - Meeting the challenges. Can. J. Plant Sci. 87:723-738.

Finneran, E. 2010. Simulation modelling of the cost of producing and utilising feeds for ruminants on Irish Farms. J. Farm Manag. 14:95-116.

Fitzgerald, J., A. Brereton, and N. Holden. 2005. Assessment of regional variation in climate on the management of dairy cow systems in Ireland using a simulation model. Grass Forage Sci. 60:283-296. https://doi.org/10.1111/j.1365-2494.2005.00479.x.

Gerlitz, C., and B. Rieder. 2013. Mining one percent of twitter: Collections, baselines, sampling. M/C J 16:620.

Gilmore, H. S., F. J. Young, D. C. Patterson, A. R. G. Wylie, R. A. Law, D. J. Kilpatrick, C. T. Elliott, and C. S. Mayne. 2011. An evaluation of the effect of altering nutrition and nutritional strategies in early lactation on reproductive performance and estrous behavior of high-yielding Holstein-Friesian dairy cows. J. Dairy Sci. 94:3510-3526. https://doi.org/10.3168/jds.2010-3547.

Hanrahan, L., N. McHugh, T. Hennessy, B. Moran, R. Kearney, M. Wallace, and L. Shalloo. 2018. Factors associated with profitability in pasture-based systems of milk production. J. Dairy Sci. 101:5474-5485. https://doi.org/10.3168/jds.2017-13223.

Hurtado-Uria, C., D. Hennessy, L. Shalloo, D. O'Connor, and L. Delaby. 2013. Relationships between meteorological data and grass growth over time in the south of Ireland. Ir. Geogr. 46:175-201. https://doi.org/10.1080/00750778.2013.865364.

Jones, J., and M. Hidiroglou. 2013. Chapter 11: Capturing, Coding, and Cleaning Survey Data. Pages 459-504 in Designing and Conducting Business Surveys. John Wiley and Sons.

Kennedy, E., M. McEvoy, J. Murphy, and M. O'Donovan. 2009. Effect of restricted access time to pasture on dairy cow milk production, grazing behaviour, and dry matter intake. J. Dairy Sci. 92:168176. https://doi.org/10.3168/jds.2008-1091. 
Kristensen, T., K. Soegaard, and I. Kristensen. 2005. Management of grasslands in intensive dairy livestock farming. Livest. Prod. Sci. 96:61-73. https://doi.org/10.1016/j.livprodsci.2005.05.024.

Läpple, D., T. Hennessy, and M. O'Donovan. 2012. Extended grazing: A detailed analysis of Irish dairy farms. J. Dairy Sci. 95:188-195. https://doi.org/10.3168/jds.2011-4512.

Lee, J., A. Clark, and J. Roche. 2013. Climate-change effects and adaptation options for temperate pasture-based dairy farming systems: a review. Grass Forage Sci. 68:485-503. https://doi.org/10 $.1111 /$ gfs. 12039 .

Lee, M., and D. Roberts. 2014. Cut and Carry: Investigating the Effects of Increasing the Proportion of Grass in the Diets of High Yielding Dairy Cows. Kenilworth: DairyCo.

Macdonald, K. A., J. Penno, J. Lancaster, and J. Roche. 2008. Effect of stocking rate on pasture production, milk production, and reproduction of dairy cows in pasture-based systems. J. Dairy Sci. 91:2151-2163. https://doi.org/10.3168/jds.2007-0630.

McKillop, J., K. Heanue, and J. Kinsella. 2018. Are all young farmers the same? An exploratory analysis of on-farm innovation on dairy and drystock farms in the Republic of Ireland. J. Agric. Educ. Ext. 24:137-151. https://doi.org/10.1080/1389224X.2018.1432494.

Meul, M., S. Van Passel, D. Fremaut, and G. Haesaert. 2012. Higher sustainability performance of intensive grazing versus zero-grazing dairy systems. Agron. Sustain. Dev. 32:629-638. https://doi.org/ 10.1007/s13593-011-0074-5.

O'Brien, B., and D. Hennessy. 2017. Scientific appraisal of the Irish grass-based milk production system as a sustainable source of premium quality milk and dairy products. Ir. J. Agric. Food Res. 56:120-129. https://doi.org/10.1515/ijafr-2017-0011.

O'Brien, D., L. Shalloo, J. Patton, F. Buckley, C. Grainger, and M. Wallace. 2012. A life cycle assessment of seasonal grass-based and confinement dairy farms. Agric. Syst. 107:33-46. https://doi.org/ 10.1016/j.agsy.2011.11.004.

O'Donnell, S., L. Shalloo, A. Butler, and B. Horan. 2008. A survey analysis of opportunities and limitations of Irish dairy farms. J. Farm Manag. 13:419-434.

O'Donovan, M., E. Lewis, T. Boland, and P. O'Kiely. 2010. Requirements of Future Grass Based Ruminant Production Systems in Ireland. Teagasc.

O'Donovan, M., E. Lewis, and P. O'Kiely. 2011. Requirements of future grass-based ruminant production systems in Ireland. Ir. J. Agric. Food Res. 50:1-21.

O'Donovan, M., and M. McEvoy. 2016. Managing your grass. Teagasc Dairy Manual. Teagasc.

O'Grady, L., M. Doherty, and F. Mulligan. 2008. Subacute ruminal acidosis (SARA) in grazing Irish dairy cows. Vet. J. 176:44-49. https://doi.org/10.1016/j.tvjl.2007.12.017.
O'Kiely, P. 2014. Beef 2014 - Grass silage. Accessed Jun. 3, 2020 https://www.teagasc.ie/media/website/animals/beef/grass-silage .pdf.

O'Loughlin, J., M. O'Donovan, and F. Kelly. 2008. Grass Based Milk Production Systems for Regions of High Rainfall and Heavy Clay Soil types. Teagasc.

Patton, D., K. Pierce, and B. Horan. 2016. Effect of stocking rate on milk and pasture productivity and supplementary feed use for spring calving pasture fed dairy systems. J. Dairy Sci. 99:59045915. https://doi.org/10.3168/jds.2015-10305.

Rankin, J. 2018. Foreword. Page 2 in Zero-Grazing: A Best Practice Guide. AgriSearch

Ruelle, E., L. Delaby, M. Wallace, and L. Shalloo. 2018. Using models to establish the financially optimum strategy for Irish dairy farms. J. Dairy Sci. 101:614-623. https://doi.org/10.3168/jds.2017 -12948 .

Shalloo, L., M. O' Donovan, L. Leso, J. Werner, E. Ruelle, A. Geoghegan, L. Delaby, and N. O'Leary. 2018. Review: Grass-based dairy systems, data and precision technologies. Animal 12:s262-s271. https://doi.org/10.1017/S175173111800246X.

Teagasc. 2018. National Farm Survey 2018. Teagasc.

Teagasc. 2019. Ten benefits of being in a discussion group. Pages 16-17 in Today's Farm, March. Teagasc.

Tongco, D. 2007. Purposive sampling as a tool for informant selection. Ethnobot. Res. Appl. 5:147-158. https://doi.org/10.17348/era.5.0 .147-158

Ullrich, L., and H. Khoudary. 2018. WhatsApp surveying guide. United Nations Development Programme.

van Vuuren, A., and A. van den Pol-van Dasselaar. 2006. Grazing systems and feed supplementation. Pages 85-101 in Fresh Herbage for Dairy Cattle. A. Elgersma, J. Dijkstra, and S. Tamminga, ed. Springer.

Wilkinson, J. M., M. Lee, J. Rivero, and T. Chamberlain. 2020. Some challenges and opportunities for grazing dairy cows on temperate pastures. Grass Forage Sci. 75:1-17. https://doi.org/10.1111/gfs .12458

\section{ORCIDS}

C. Holohan $\odot$ https://orcid.org/0000-0001-5752-3986

T. Russell ৫ https://orcid.org/0000-0003-0799-360X

F. J. Mulligan ๑ https://orcid.org/0000-0002-1787-0788

K. M. Pierce (ㄴ) https://orcid.org/0000-0002-2056-6189

M. B. Lynch ๑ https://orcid.org/0000-0002-5301-6845 